\title{
The First Case of Invasive Bacteroides Dorei Infection Detected in a Mycotic Aortic Aneurysm Patient-Raising A Rebellion of Major Indigenous Bacteria in Humans: A Case Report and Review
}

Takayuki Matsuoka ( $\square$ tmatsuoka-kb@tohoku-mpu.ac.jp )

Tohoku lka Yakka Daigaku https://orcid.org/0000-0002-7658-4829

Takuya Shimizu

Tohoku lka Yakka Daigaku

Tadanori Minagawa

Tohoku Ika Yakka Daigaku

Wakiko Hiranuma

Tohoku lka Yakka Daigaku

Miki Takeda

Tohoku Ika Yakka Daigaku

Risako Kakuta

Tohoku Daigaku

Shunsuke Kawamoto

Tohoku Ika Yakka Daigaku

\section{Case Report}

Keywords: Bacteroides dorei, mycotic aortic aneurysm, 16S rRNA gene sequencing, microbiota, indigenous intestinal bacteria, mass spectrometry

Posted Date: September 10th, 2020

DOl: https://doi.org/10.21203/rs.3.rs-74102/v1

License: (c) (1) This work is licensed under a Creative Commons Attribution 4.0 International License. Read Full License

Version of Record: A version of this preprint was published at BMC Infectious Diseases on June 30th, 2021. See the published version at https://doi.org/10.1186/s12879-021-06345-8. 


\section{Abstract}

Background: Bacteroides dorei is an anaerobic, gram-negative bacterium first described in 2006. Due to the high similarity in mass spectrum patterns between $B$. dorei and Bacteroides vulgatus, discriminating these species is arduous in clinical practice. In recent decades, $16 \mathrm{~S}$ rRNA gene sequencing has been a complementary method for distinguishing taxonomically close bacteria to the genus and species levels, including $B$. dorei and $B$. vulgatus. Accordingly, $B$. dorei has been shown to contribute to some diseases, including type 1 autoimmune diabetes mellitus and atherosclerotic diseases. Nevertheless, there are no reports on invasive infectious disease caused by $B$. dorei. This report describes the first case of $B$. dorei presenting direct invasion and colonisation into human tissue, providing a warning for the previously proposed application of $B$. dorei as live biotherapeutics for atherosclerotic diseases.

Case presentation: A 78-year-old man admitted with suspicion for mycotic thoracic aortic aneurysm was diagnosed by enhanced computed tomography scan, exhibiting the appearance of infection and dissection at the distal aortic arch. Despite strict blood pressure control and empirical antibiotic therapy, the patient's condition worsened. For the prevention of aneurysmal rupture and elimination of infectious foci, the patient underwent surgical treatment, and the resected specimen was subjected to tissue culture and $16 \mathrm{~S}$ rRNA gene sequencing analysis to identify pathogenic bacteria. A few days after the surgery, culture and sequencing results revealed that the pathogen was $B$. dorei/ vulgatus and $B$. dorei, respectively. The patient was successfully treated by appropriate antibacterial therapy, improved and was transferred to another hospital for rehabilitation at postoperative day 34. There was no recurrence of symptoms after the patient transfer.

Conclusions: This report describes the first case of invasive infectious disease caused by $B$. dorei, casting a shadow over its utilisation as a probiotic for atherosclerotic diseases.

\section{Background}

Bacteroides dorei is a gram-negative and anaerobic rod generally isolated from the human and animal gastrointestinal tract [1] and one of the cardinal indigenous bacteria in humans [2]. In clinical settings, matrix-assisted laser desorption ionisation time-of-flight mass spectrometry (MALDI-TOF MS) analysis has prominently contributed to the identification of pathogenic bacteria and fungi, and its identification accuracy was estimated as high as $84 \%$ for species and $92 \%$ for genera [3]. However, it is known that this methodology has some limitations for taxonomically close species or anaerobic bacteria. Some researchers have shown the low performance of MALDI-TOF MS for identifying anaerobic bacteria spp., partially due to insufficient commercial mass spectrum reference libraries, resulting in the misidentification of pathogens, e.g., B. dorei to Bacteroides vulgatus [4-7]. In the last decade, 16S rRNA gene sequencing for bacterial identification has been applicable in many facilities. This polymerase chain reaction (PCR)-based method is highly potent for discriminating phylogenetically close bacteria to the genus and species levels; therefore, it has been relevant as a complementary method for blood culture, MALDI-TOF MS, and conventional phenotypic screening tests to identify bacterial pathogens [8]. Recently, 
the role of $B$. dorei as an immunomodulator in autoimmune disease has been uncovered [9]. Other reports also showed that alteration of the abundance of Bacteroides species in the intestinal microbiota was associated with susceptibility to autoimmune disease or atherosclerotic diseases; they are thus assumed to be therapeutic targets for these diseases, especially in the form of probiotics or biotherapy [10]. However, there are almost no reports indicating the direct infectious pathogenesis of $B$. dorei. This report describes the first case of $B$. dorei as a pathogen of invasive infectious disease, suggesting the need for caution in the usage of $B$. dorei as a biotherapeutic material.

\section{Case Presentation}

A 78-year-old man presented with intermitted chest-back pain and was admitted to our hospital with suspicion of a mycotic thoracic aortic aneurysm. On the day of admission, the patient was afebrile and showed unremarkable manifestations except for dysphoria of his back. A contrast-enhanced computed tomography (eCT) scan confirmed the appearance of a mycotic thoracic aortic aneurysm and dissection at the distal arch with intramural fluid-density collection and periaortic inflammatory changes (Fig. 1). We started empiric intravenous antibiotic therapy with meropenem, vancomycin and micafungin. After three days, we assessed the effectiveness of the treatment by laboratory examination and ECT. Despite strict blood pressure control and broad-spectrum antibiotic therapy, inflammation scores became exacerbated, represented by elevated C-reactive protein (CRP), procalcitonin (Pct), and white blood cell (WBC) count (CRP 11.61 to $28.71 \mathrm{mg} / \mathrm{dl}$, WBC 9.920 to $17,800 / \mu \mathrm{l}$, and Pct 0.34 to $0.84 \mathrm{ng} / \mathrm{ml}$ ), and the patient suffered from a high fever up to $39.9^{\circ} \mathrm{C}$. For the prevention of aneurysmal rupture and the elimination of infected foci, the patient underwent ascending aorta and aortic arch resection and subsequent total arch replacement with rifampicin immersed in artificial vessels on day five, and the resected infected tissue was subjected to pathological analysis (Fig. 2), culture examination and 16S rRNA gene sequence analysis (Fig. 3) to identify the pathogen. A few days after surgical treatment, the culture and sequencing results revealed $B$. vulgatus/dorei and $B$. dorei (Fig. 3 and additional file 1-2) as the pathogen, respectively. By the determination of the pathogen and susceptibility tests, the three antibiotic therapies could be de-escalated and stepwise shifted to a single metronidazole p.o. therapy. The patient satisfactorily improved and was transferred to another hospital for rehabilitation at postoperative day 34 . There was no recurrence of symptoms after patient transfer.

\section{Discussion And Conclusions}

Anaerobic bacteria, including Bacteroides spp., usually reside in the lower intestinal tract as indigenous bacteria. However, they are sometimes detected as pathogens in infectious disease patients. Anaerobe infection can be highly lethal and life threatening, and its mortality rate is estimated to be as high as $40 \%$ [11]. Therefore, it is crucial to identify pathogenic bacteria immediately and initiate appropriate antibiotic therapy targeting the identified specific pathogen. In the last decade, in addition to conventional culture tests, MALDI-TOF MS has been widely used for clinical examination. This method is capable of detecting pathogens in a few minutes after applying samples, but this mass spectrum-based bacterial 
identification has some limitations among bacteria having similar protein compositions or uncommon bacterial species, partially due to incomplete reference databases. Because of only $5 \%$ gene sequence divergence between $B$. dorei and $B$. vulgatus [1], two major MALDI-TOF MS systems commercially available misidentify $B$. dorei as $B$. vulgatus or cannot distinguish them $[12,13]$. Our facility also employs the MALDI-TOF MS system for the identification of pathogens and could not discriminate between $B$. dorei and B. vulgatus, determining the pathogen as "B. vulgatus/dorei" in this case.

16S rRNA gene sequencing is a highly potent molecular biological approach for identifying specific bacteria to the species level, particularly in the case of uncommon, slow-growing or uncultivable bacteria, such as minor anaerobes. Due to the inexpensiveness and easy availability of PCR and DNA sequencing needed for this method, it has been a complementary examination tool for the accurate identification of bacteria and the discovery of novel bacterial species in clinical and laboratory settings [14]. In 2019, J. S. Johnson et al. reported the interspecies sequence entropy of the $16 \mathrm{~S}$ rRNA gene, depicting that the V2, V3, V6, and V9 regions had relatively high sequence variations and noted the validity of sub-regional sequencing for discriminating closely related bacteria from specific taxa [15]. As preliminary experiments, we initially amplified the full, first-half and second-half lengths of the 16S rRNA gene sequence, and thereby, it was shown that the second-half sequence was prone to more effective amplification and that amplicon sequencing could identify specific bacteria satisfactorily (data not shown). In this case, through amplification and sequencing of the V5-V9 segments, we successfully identified $B$. dorei as a pathogen with $100 \%$ sequence identity. Altogether, it was corroborated that partial 16S rRNA gene sequencing, which included at least two of the four high variant regions mentioned above, has sufficient detectability and capability of discriminating specific bacteria among allied species.

Under this sequencing-based bacterial identification, the pathophysiology of $B$. dorei has been gradually uncovered. When we searched the PubMed database using the keyword "Bacteroides dorei", only 50 articles were published by June $1 \mathrm{st}, 2020$. It is seemingly innocuous in healthy individuals, as Bacteroidetes and Firmicutes constitute over $90 \%$ of healthy gut microbial assemblage [16]. However, it has been demonstrated that the $B$. dorei proportion in the gut microbiota is responsible for a variety of diseases, including autoimmune type 1 diabetes mellitus [9, 17-22], colorectal diseases [23-26], atherosclerotic diseases [27-30], and even Parkinson's disease [31]. On the other hand, there is almost no report regarding $B$. dorei as a cause of infectious diseases or even a part of its contagious process, which consists of tissue invasion, multiplication and colonisation and infliction of host tissue damage by cytotoxic materials or direct interactions. In immunocompromised or dysbiosis states resulting in a permeable gut and impairment of mucosal barriers, pathogens may invade nearby tissues or the systemic circulation, consequently initiating infectious diseases. Despite the assumption of these mechanisms, there is no sufficient evidence for understanding the pathogenesis of $B$. dorei. As a result, this report describes the first case of invasive infectious disease caused by $B$. dorei. Further studies are needed to elucidate its infectious processes.

The association of dysbacteriosis or alteration of the $B$. dorei proportion in the gut microbiota with these diseases might be a target for preventative or therapeutic interventions. Some researchers have proposed 
using some indigenous bacteria as pre-/probiotics for modulating gut bacterial composition, including $B$. dorei itself $[10,29,30,32-35]$. However, as microbiome composition is influenced by daily meals, eating habits and geography and temporally varies even in individuals, the efficacy of probiotic usage may be definite in a specific condition. Furthermore, as the gut microbiota forms complex systems (e.g., metabolic network, interaction with an immune system or inter-microbial interaction), the effect of modification of specific bacterial abundance is not necessarily predictable [36]. Moreover, due to its invasive potential causing infectious diseases, such as in this case report, considerable attention must be paid to the use of $B$. dorei as a probiotic. Additional studies regarding the application of probiotics or modulating strategies of the gut microbiota are needed.

The metabolic profile of $B$. dorei has also been studied and has shown its uniqueness [37-41]. To date, only two bacteria have been identified with cholesterol-reducing capacity in a human microbial community, Eubacterium coprostanoligenes and B. dorei strain D8 [42, 43], which is proposed to have protective roles for atherosclerosis. However, this report presented a case of an infected aortic aneurysm caused by $B$. dorei detected from a surgically dissected atherosclerotic lesion. This contradictory aspect can be partially explained by the microbial metabolic features described in one report in which Bacteroides thetaiotaomicron was shown to selfishly or exclusively metabolise yeast mannan [44]. These results may imply that some bacteria have preferences for a specific tissue site, such as atherosclerotic lesions or microbial community sites. As $B$. dorei strains have the potential to metabolise cholesterol, they may be predisposed to colonise atherosclerotic tissues with plaque deposited by fat, cholesterol and calcium. Therefore, $B$. dorei potentially causes a mycotic aneurysm or infective endocarditis in atherosclerotic patients. This fact also gives us warning regarding the utilisation of $B$. dorei as a biotherapeutic tool, particularly in the form of live bacteria.

In conclusion, we report the first case of invasive infectious disease by $B$. dorei in a mycotic thoracic aneurysm patient, which disagrees with the protective roles of $B$. dorei in atherosclerotic diseases.

\section{Materials And Methods}

\section{DNA isolation from infectious tissue and verification of DNA purity}

DNA isolation from infectious tissue and purification of the extracted DNA was carried out with the NucleoSpin ${ }^{\circledR}$ Tissue (MACHEREY-NAGEL (MN), \#740952) and Monarch ${ }^{\circledR}$ Genomic DNA Purification Kits (NEW ENGLAND BioLabs Inc. (NEB), \#T3010) according to the manufacturer's instructions. The DNA concentration was determined by a NanoDrop One spectrophotometer (Thermo Scientific ${ }^{\mathrm{TM}}$ ), as well as its purity. The extracted DNA samples were stored at $-20^{\circ} \mathrm{C}$. To prevent interference with the following enzymatic reaction, DNA was eluted from the spin column with DNase/RNase-free water. Throughout the protocol (DNA extraction/purification, primer aliquoting, and 16S rRNA gene amplification), nuclease-free plastics were used unless supplied with the kit: DNA LoBind Tubes (Eppendorf) and OneTouch tips (Sorenson BioScience, Inc.). 


\section{Positive control}

As a positive control, Escherichia coli DH5-alpha (Takara, \#9057) was incubated with shaking overnight at $37^{\circ} \mathrm{C}$ in LB broth. Before reaching the confluent state, the bacteria were harvested by centrifugation and subjected to lysis following genomic DNA extraction by using a Monarch ${ }^{\circledR}$ Genomic DNA Purification Kit (NEB, \#T3010) according to the manufacturer's instructions.

\section{S rRNA gene amplification}

For detection of the bacterial 16S rRNA gene, PCR amplification of the V5-V9 region was performed using the following universal primers (forward primer (800F): 5'- GGATTAGATACCCTGGTA -3' and reverse primer (1500R): 5'- TACCTTGTTACGACTT -3'). Amplification was performed with $1.5 \mu \mathrm{g}$ of DNA per reaction, the primers at a final concentration of $2 \mu \mathrm{M}$, and Tks Gflex ${ }^{T M}$ DNA Polymerase (Takara, \#R091A). PCR was performed using the following conditions: $60 \mathrm{~s}$ of denaturation at $94{ }^{\circ} \mathrm{C} ; 35$ cycles of denaturation at $98{ }^{\circ} \mathrm{C}$ for $10 \mathrm{~s}$, annealing at $51^{\circ} \mathrm{C}$ for $60 \mathrm{~s}$, and elongation at $68^{\circ} \mathrm{C}$ for $60 \mathrm{~s}$; and a final extension at $72{ }^{\circ} \mathrm{C}$ for $10 \mathrm{~min}$. Negative (nuclease-free and DNA-free water) and positive controls (50 ng of $E$. coli genomic DNA) were also amplified. After completion of the PCR, the amplicons were electrophoresed on a 1.5\% agarose gel and purified by gel extraction with a Monarch ${ }^{\circledR}$ DNA Gel Extraction Kit (NEB, \#T1020) according to the manufacturer's instructions.

\section{Sequencing and taxonomical identification}

The concentration and quality of the PCR amplicons were evaluated before Sanger sequencing. Sequencing was performed by a Sanger sequencing service (GENEWIZ Inc., South Plainfield, NJ, USA) following the sample submission guidelines in which the samples were composed of $10 \mathrm{ng}$ of purified PCR amplicon and $5 \mu \mathrm{M} 800 \mathrm{~F}$ or $1500 \mathrm{R}$ sequencing primer. Sequence contigs were constructed and analysed using bioinformatics software (CLC Main Workbench 20, QIAGEN Digital Insights, Redwood City, USA). Full sequence reads were analysed for initial identification using Nucleotide BLAST (http://www.ncbi.nlm.nih.gov/blast/cg).

\section{Clinical pathogenic bacterial identification}

The isolates were initially identified by MALDI-TOF MS using a BRUKER MALDI Biotyper system (Bruker Daltonics, Bremen, Germany). The reference library of spectra was MBT Compass Library version 4.5.1, and a log score of 2.0 was used as the threshold for species identification.

\section{List Of Abbreviations}

B. dorei

Bacteroides dore; $B$. vulgatus:Bacteroides vulgatus; CRP:C-reactive protein; eCT:contrast-enhanced computed tomography; LPS:lipopolysaccharide; MALDI-TOF MS:matrix-assisted laser desorption 
ionisation time-of-flight mass spectrometry; PCR:polymerase chain reaction; Pct:procalcitonin; rRNA:ribosomal RNA; WBC: white blood cell

\section{Declarations}

\section{Ethics approval and consent to participate}

Written consent for clinical sample analysis was obtained from the patient. This study was approved by the institutional review boards of the Independent Ethics Committee of Tohoku Medical and Pharmaceutical University Hospital (reference number: 2018-2-105).

\section{Consent for publication}

Informed consent for the publication of this case report was obtained from the patient.

\section{Availability of data and materials}

The datasets supporting the conclusions of this article are included within the article and its additional file.

\section{Competing interests}

The authors declare that they have no competing interests.

\section{Funding}

This work was supported by a Grant-in-Aid for Early-Career Scientists from the Japan Society for the Promotion of Science (JSPS) (KAKENHI, grant No. JP19K18190).

\section{Authors' contributions}

TM analysed and interpreted the patient data and was a major contributor in writing the manuscript. TS, $\mathrm{TM}, \mathrm{WH}$, and MT contributed to interpreting the patient data. RK advised on the research ideas for this study. SK supervised this study and the patient's therapy. All authors read and approved the final manuscript.

\section{Acknowledgements}

The authors thank the patient and his family for their consent to participate in this study. We also appreciate all medical staff's cooperation and care of the patient.

\section{References}

1. Bakir MA, Sakamoto M, Kitahara M, Matsumoto M, Benno Y: Bacteroides dorei sp. nov., isolated from human faeces. Int J Syst Evol Microbiol 2006, 56(Pt 7):1639-1643. 
2. Qin J, Li R, Raes J, Arumugam M, Burgdorf KS, Manichanh C, Nielsen T, Pons N, Levenez F, Yamada T et al: A human gut microbial gene catalogue established by metagenomic sequencing. Nature 2010 , 464(7285):59-65.

3. Li Y, Shan M, Zhu Z, Mao X, Yan M, Chen Y, Zhu Q, Li H, Gu B: Application of MALDI-TOF MS to rapid identification of anaerobic bacteria. BMC Infect Dis 2019, 19(1):941.

4. Barba MJ, Fernandez A, Oviano M, Fernandez B, Velasco D, Bou G: Evaluation of MALDI-TOF mass spectrometry for identification of anaerobic bacteria. Anaerobe 2014, 30:126-128.

5. Huang YL, Sun QL, Li JP, Hu YY, Zhou HW, Zhang R: Evaluation of an in-house MALDI-TOF MS rapid diagnostic method for direct identification of micro-organisms from blood cultures. J Med Microbiol 2019, 68(1):41-47.

6. Veloo AC, Knoester M, Degener JE, Kuijper EJ: Comparison of two matrix-assisted laser desorption ionisation-time of flight mass spectrometry methods for the identification of clinically relevant anaerobic bacteria. Clin Microbiol Infect 2011, 17(10):1501-1506.

7. Justesen US, Holm A, Knudsen E, Andersen LB, Jensen TG, Kemp M, Skov MN, Gahrn-Hansen B, Moller JK: Species identification of clinical isolates of anaerobic bacteria: a comparison of two matrix-assisted laser desorption ionization-time of flight mass spectrometry systems. J Clin Microbio/ 2011, 49(12):4314-4318.

8. Akram A, Maley M, Gosbell I, Nguyen T, Chavada R: Utility of 16S rRNA PCR performed on clinical specimens in patient management. Int $J$ Infect Dis 2017, 57:144-149.

9. Vatanen T, Kostic AD, d'Hennezel E, Siljander H, Franzosa EA, Yassour M, Kolde R, Vlamakis H, Arthur TD, Hamalainen AM et al: Variation in Microbiome LPS Immunogenicity Contributes to Autoimmunity in Humans. Cell 2016, 165(6):1551.

10. O'Toole PW, Marchesi JR, Hill C: Next-generation probiotics: the spectrum from probiotics to live biotherapeutics. Nat Microbiol 2017, 2:17057.

11. Kim J, Lee Y, Park Y, Kim M, Choi JY, Yong D, Jeong SH, Lee K: Anaerobic Bacteremia: Impact of Inappropriate Therapy on Mortality. Infect Chemother 2016, 48(2):91-98.

12. La Scola B, Fournier PE, Raoult D: Burden of emerging anaerobes in the MALDI-TOF and 16S rRNA gene sequencing era. Anaerobe 2011, 17(3):106-112.

13. van Veen SQ, Claas EC, Kuijper EJ: High-throughput identification of bacteria and yeast by matrixassisted laser desorption ionization-time of flight mass spectrometry in conventional medical microbiology laboratories. J Clin Microbiol 2010, 48(3):900-907.

14. Yarza P, Yilmaz P, Pruesse E, Glockner FO, Ludwig W, Schleifer KH, Whitman WB, Euzeby J, Amann R, Rossello-Mora R: Uniting the classification of cultured and uncultured bacteria and archaea using 16S rRNA gene sequences. Nat Rev Microbio/ 2014, 12(9):635-645.

15. Johnson JS, Spakowicz DJ, Hong BY, Petersen LM, Demkowicz P, Chen L, Leopold SR, Hanson BM, Agresta HO, Gerstein $\mathrm{M}$ et al: Evaluation of 16S rRNA gene sequencing for species and strain-level microbiome analysis. Nat Commun 2019, 10(1):5029. 
16. Eckburg PB, Bik EM, Bernstein CN, Purdom E, Dethlefsen L, Sargent M, Gill SR, Nelson KE, Relman DA: Diversity of the human intestinal microbial flora. Science 2005, 308(5728):1635-1638.

17. Davis-Richardson AG, Ardissone AN, Dias R, Simell V, Leonard MT, Kemppainen KM, Drew JC, Schatz $D$, Atkinson MA, Kolaczkowski $B$ et al: Bacteroides dorei dominates gut microbiome prior to autoimmunity in Finnish children at high risk for type 1 diabetes. Front Microbio/ 2014, 5:678.

18. Davis-Richardson AG, Triplett EW: A model for the role of gut bacteria in the development of autoimmunity for type 1 diabetes. Diabetologia 2015, 58(7):1386-1393.

19. Cinek O, Kramna L, Lin J, Oikarinen S, Kolarova K, llonen J, Simell O, Veijola R, Autio R, Hyoty H: Imbalance of bacteriome profiles within the Finnish Diabetes Prediction and Prevention study: Parallel use of $16 \mathrm{~S}$ profiling and virome sequencing in stool samples from children with islet autoimmunity and matched controls. Pediatr Diabetes 2017, 18(7):588-598.

20. Higuchi BS, Rodrigues N, Gonzaga MI, Paiolo JCC, Stefanutto N, Omori WP, Pinheiro DG, Brisotti JL, Matheucci E, Jr., Mariano VS et al: Intestinal Dysbiosis in Autoimmune Diabetes Is Correlated With Poor Glycemic Control and Increased Interleukin-6: A Pilot Study. Front Immunol 2018, 9:1689.

21. Abdellatif AM, Jensen Smith H, Harms RZ, Sarvetnick NE: Human Islet Response to Selected Type 1 Diabetes-Associated Bacteria: A Transcriptome-Based Study. Front Immunol 2019, 10:2623.

22. Wu Y, Bible PW, Long S, Ming WK, Ding W, Long Y, Wen X, Li X, Deng X, Deng $Y$ et al: Metagenomic analysis reveals gestational diabetes mellitus-related microbial regulators of glucose tolerance. Acta Diabeto/ 2020, 57(5):569-581.

23. Guo M, Xu E, Ai D: Inferring Bacterial Infiltration in Primary Colorectal Tumors From Host Whole Genome Sequencing Data. Front Genet 2019, 10:213.

24. Heida FH, van Zoonen A, Hulscher JBF, Te Kiefte BJC, Wessels R, Kooi EMW, Bos AF, Harmsen HJM, de Goffau MC: A Necrotizing Enterocolitis-Associated Gut Microbiota Is Present in the Meconium: Results of a Prospective Study. Clin Infect Dis 2016, 62(7):863-870.

25. Vidal R, Ginard D, Khorrami S, Mora-Ruiz M, Munoz R, Hermoso M, Diaz S, Cifuentes A, Orfila A, Rossello-Mora R: Crohn associated microbial communities associated to colonic mucosal biopsies in patients of the western Mediterranean. Syst App/ Microbiol 2015, 38(6):442-452.

26. Gustafsson RJ, Ohlsson B, Benoni C, Jeppsson B, Olsson C: Mucosa-associated bacteria in two middle-aged women diagnosed with collagenous colitis. World J Gastroenterol 2012, 18(14):16281634.

27. Yoshida N, Emoto T, Yamashita T, Watanabe H, Hayashi T, Tabata T, Hoshi N, Hatano N, Ozawa G, Sasaki $\mathrm{N}$ et al: Bacteroides vulgatus and Bacteroides dorei Reduce Gut Microbial Lipopolysaccharide Production and Inhibit Atherosclerosis. Circulation 2018, 138(22):2486-2498.

28. Zhang $Y, X u J$, Wang $X$, Ren X, Liu Y: Changes of intestinal bacterial microbiota in coronary heart disease complicated with nonalcoholic fatty liver disease. BMC Genomics 2019, 20(1):862.

29. Yoshida N, Sasaki K, Sasaki D, Yamashita T, Fukuda H, Hayashi T, Tabata T, Osawa R, Hirata KI, Kondo A: Effect of Resistant Starch on the Gut Microbiota and Its Metabolites in Patients with Coronary Artery Disease. J Atheroscler Thromb 2019, 26(8):705-719. 
30. Kazemian N, Mahmoudi M, Halperin F, Wu JC, Pakpour S: Gut microbiota and cardiovascular disease: opportunities and challenges. Microbiome 2020, 8(1):36.

31. Petrov VA, Saltykova IV, Zhukova IA, Alifirova VM, Zhukova NG, Dorofeeva YB, Tyakht AV, Kovarsky BA, Alekseev DG, Kostryukova ES et al: Analysis of Gut Microbiota in Patients with Parkinson's Disease. Bull Exp Biol Med 2017, 162(6):734-737.

32. Thomson P, Medina DA, Ortuzar V, Gotteland M, Garrido D: Anti-inflammatory effect of microbial consortia during the utilization of dietary polysaccharides. Food Res Int 2018, 109:14-23.

33. Hou Q, Zhao F, Liu W, Lv R, Khine WWT, Han J, Sun Z, Lee YK, Zhang H: Probiotic-directed modulation of gut microbiota is basal microbiome dependent. Gut Microbes 2020:1-20.

34. Zhang M, Fan X, Fang B, Zhu C, Zhu J, Ren F: Effects of Lactobacillus salivarius Ren on cancer prevention and intestinal microbiota in 1, 2-dimethylhydrazine-induced rat model. $J$ Microbiol 2015, 53(6):398-405.

35. Santilli AD, Russell JT, Triplett EW, Whitehead KJ, Whitehead DC: Non-lethal growth inhibition by arresting the starch utilization system of clinically relevant human isolates of Bacteroides dorei. Medchemcomm 2019, 10(11):1875-1880.

36. Gutierrez N, Garrido D: Species Deletions from Microbiome Consortia Reveal Key Metabolic Interactions between Gut Microbes. mSystems 2019, 4(4).

37. Pedersen RM, Marmolin ES, Justesen US: Species differentiation of Bacteroides dorei from Bacteroides vulgatus and Bacteroides ovatus from Bacteroides xylanisolvens - back to basics. Anaerobe 2013, 24:1-3.

38. Kim JK, Shin SY, Moon JS, Li L, Cho SK, Kim TJ, Han NS: Isolation of dextran-hydrolyzing intestinal bacteria and characterization of their dextranolytic activities. Biopolymers 2015, 103(6):321-327.

39. Sakanaka M, Sugiyama Y, Nara M, Kitakata A, Kurihara S: Functional analysis of arginine decarboxylase gene speA of Bacteroides dorei by markerless gene deletion. FEMS Microbiol Lett 2018, 365(4).

40. Chassard C, Goumy V, Leclerc M, Del'homme C, Bernalier-Donadille A: Characterization of the xylandegrading microbial community from human faeces. FEMS Microbiol Ecol 2007, 61(1):121-131.

41. Nemoto TK, Ono T, Kobayakawa T, Ohara-Nemoto Y: Characterization of bacterial acylpeptidyloligopeptidase. Biochimie 2019, 163:50-57.

42. Gerard P, Lepercq P, Leclerc M, Gavini F, Raibaud P, Juste C: Bacteroides sp. strain D8, the first cholesterol-reducing bacterium isolated from human feces. Appl Environ Microbiol 2007, 73(18):5742-5749.

43. Ren D, Li L, Schwabacher AW, Young JW, Beitz DC: Mechanism of cholesterol reduction to coprostanol by Eubacterium coprostanoligenes ATCC 51222. Steroids 1996, 61(1):33-40.

44. Cuskin F, Lowe EC, Temple MJ, Zhu Y, Cameron E, Pudlo NA, Porter NT, Urs K, Thompson AJ, Cartmell $A$ et al: Human gut Bacteroidetes can utilize yeast mannan through a selfish mechanism. Nature 2015, 517(7533):165-169. 


\section{Figures}

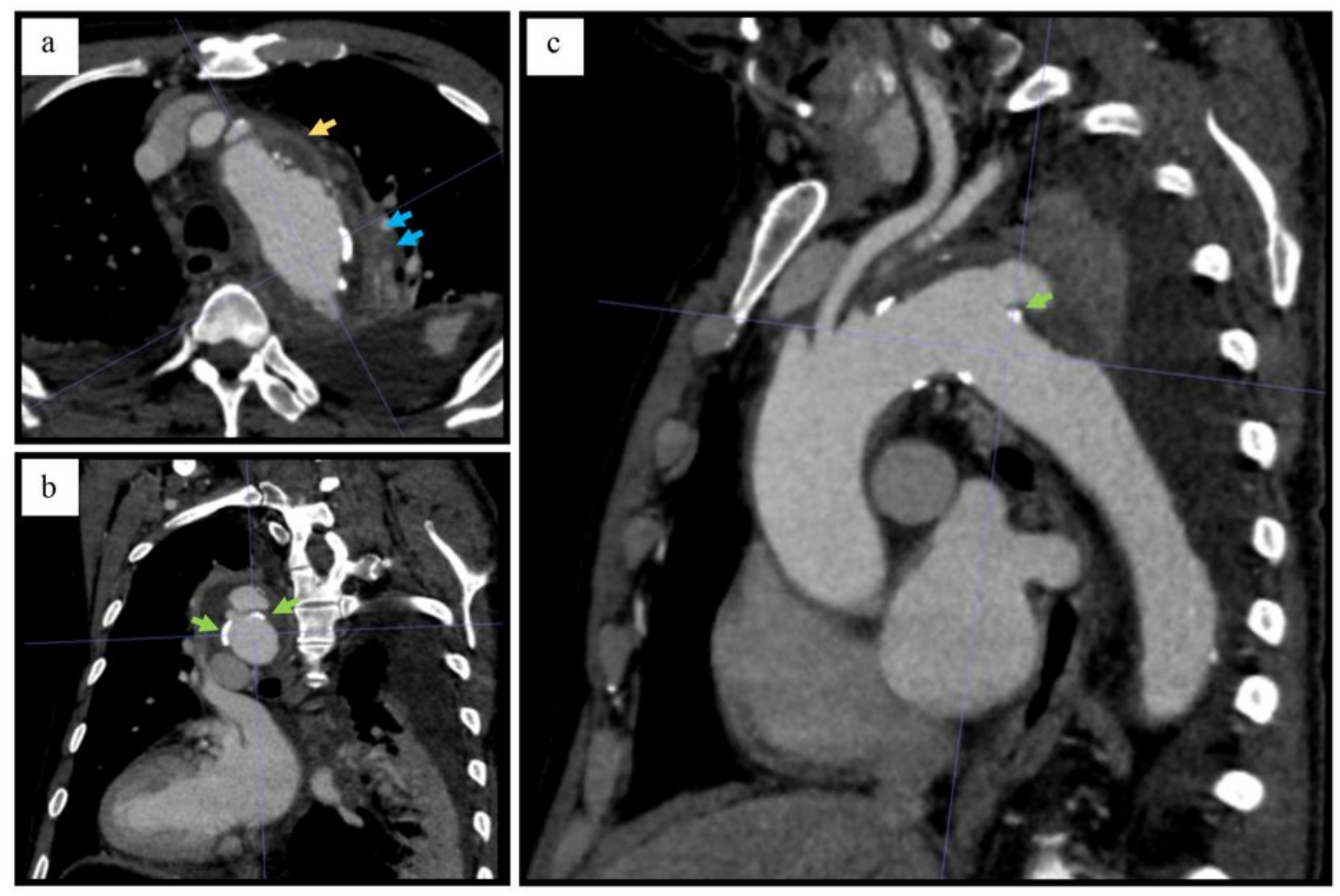

\section{Figure 1}

Contrast-enhanced computed tomography scan on admission of the patient. (a) An axial view shows the distal aortic arch aneurysm with perianeurysmal fluid-density collection (yellow arrow) and periaortic inflammatory changes (blue arrows). Coronal (b) and sagittal (c) views show the dislocation of intimal calcification (green arrows) and the appearance of aortic dissection. 

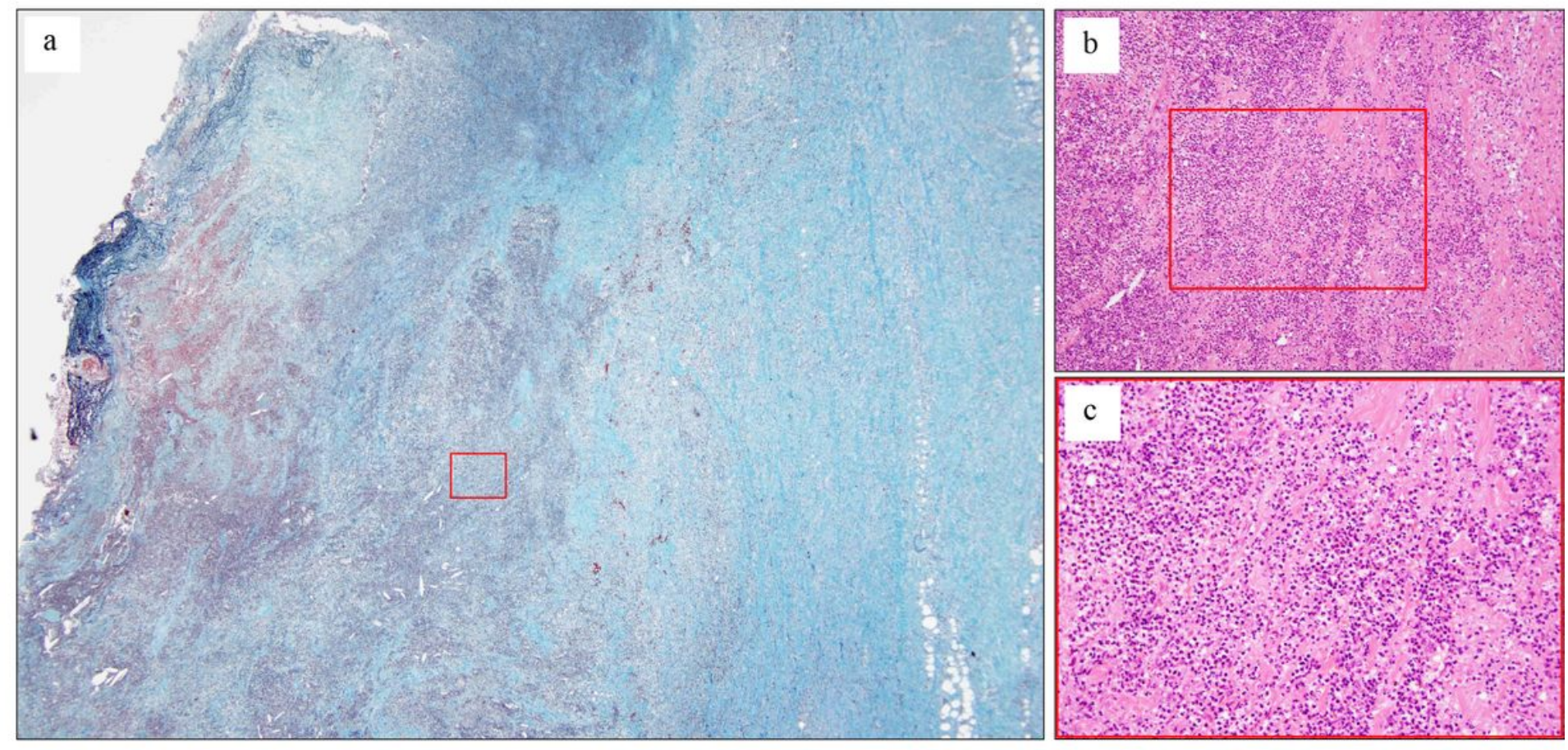

\section{Figure 2}

Pathological examination of the resected aorta. Microscopic examination of the resected specimen was achieved with Elastica-Masson staining (a) and Hematoxylin and eosin staining (b, c). (a) Significant immunocyte infiltration is seen in the sub-adventitial layer, depicting purulent inflammation. (b, c) Abundant neutrophils infiltrate into the intramural area of the infected arterial wall, forming an abscess. 


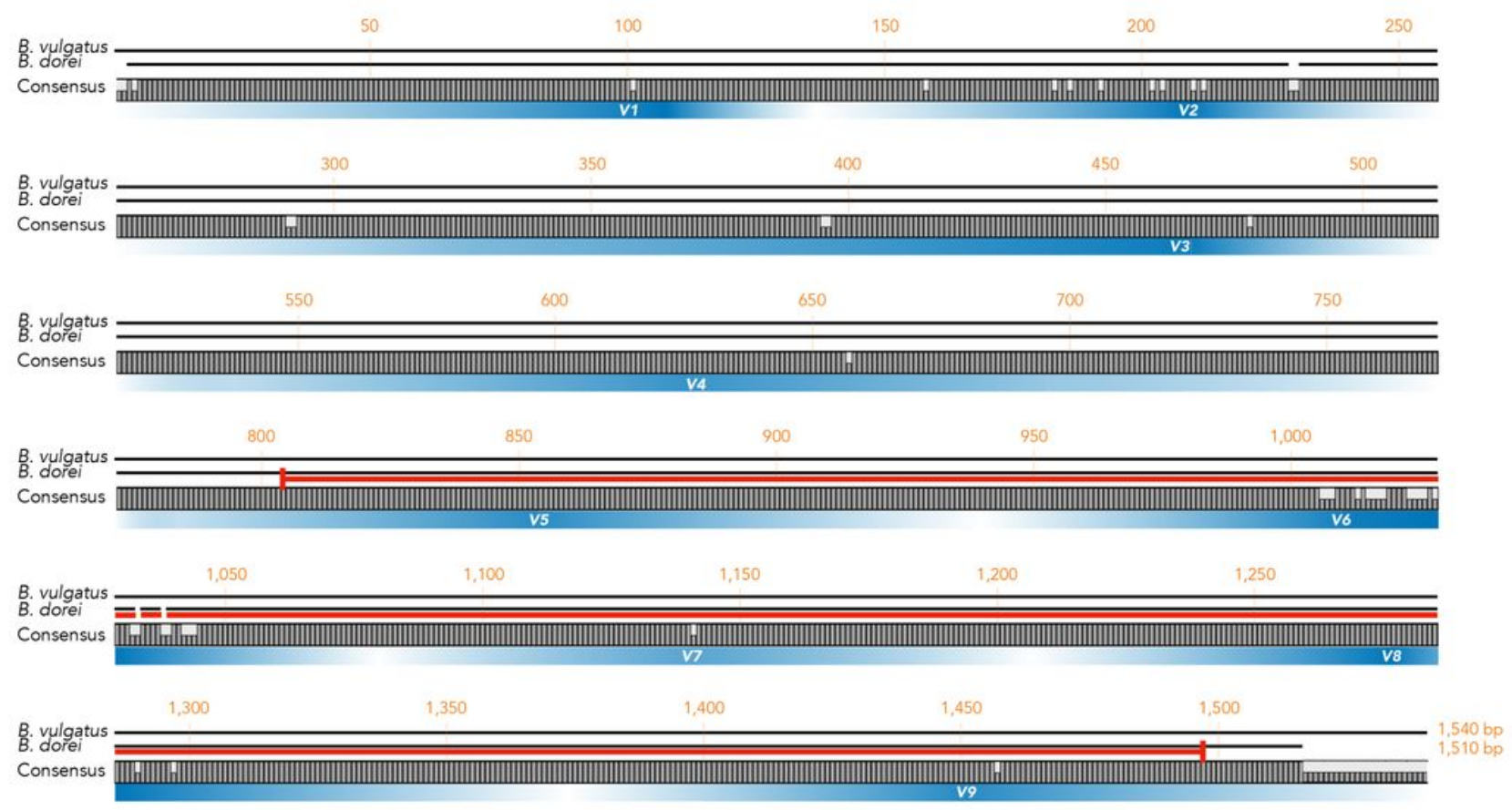

\section{Figure 3}

16S rRNA gene sequence analysis for the identification of pathogenic bacteria. Bacteroides dorei (DSM 17855) and Bacteroides vulgatus (ATCC8482(T)) 16S rRNA gene sequences are aligned with the consensus, with a concordance rate as high as $97 \%$. V1-V9 represent an inter-species variant region in its gene sequence, and a red bar indicates the sequencing range for identifying pathogens in this study. $\mathrm{B}$. dorei was identified as a pathogen in this patient, with $100 \%$ sequence identity.

\section{Supplementary Files}

This is a list of supplementary files associated with this preprint. Click to download.

- Additionalfile.docx

- Additionalfile2.pdf

- Additionalfile1.xlsx 